\title{
Innovation in Teaching Economics: The case of Greek Post - Secondary Level
}

\author{
Eleni Tsami \\ Department of Statistics \& Insurance Science, University of Piraeus -Greece
}

\begin{abstract}
This paper is a part of a research in Teaching Economics with the use of Technologies in Post Secondary level.

The aim of this paper is to challenge the hypothesis: "the use of computers and the internet in the teaching of economic modules does not affect student learning and retention".

Research restrictions stipulated that the research was to be conducted at Institutes for Professional Training (IEK) of the Organization for Professional Education and Training (OEEK), during spring semester, 2007-2008. 70 students, in total, participated in the research, comprising three classes of 25, 25 and 20 students respectively. "Money - Banks - Elements of Banking Techniques" was the course attended by these three classes. The lessons of the three classes took place in the computer laboratory where 25 computers were installed.
\end{abstract}

The result of this research is that students like to use of computers in Economic classes and learn more with the use of New Technologies.

Keywords: Innovation, Education, Technologies, Computer.

\section{Introduction}

Although the use of New Technologies in economic pedagogy has been growing, it has not received the corresponding attention in the economic education literature. Almost no studies to date have measured the impact of using technology on student learning and retention, perceptions of instructor effectiveness, and changes in attitudes towards economics.

We report the results from classroom experiments that tested the influence of computer use on economic education.

Using computer resources to enhance economic courses has two principal advantages for students.

First, these resources offer a new medium of interaction that complements classroom instruction and facilitates learning. Second, they offer students the opportunity to learn and use technology and yield positive externalities for future academic and career paths.

The important role of informatics in the educational process is beyond arguments and this does not only mean introducing a new tool in all levels of teaching but developing a new dimension in educational technology as well. Computers are being diversely used in education, although there are various views as to their effectiveness in teaching. However, it has been claimed by many researchers that computers can be of invaluable assistance both to teachers and students in teaching economics.

Computers can offer learning opportunities with the general aim to enhance teachers' communicability of knowledge and students' understanding. Thus, teachers of economics are aware of the benefits of technology and are trying to get acquainted

Copyright (C) 2011. Eleni Tsami . This is an open access article distributed under the Creative Commons Attribution License unported 3.0, which permits unrestricted use, distribution, and reproduction in any medium, provided that original work is properly cited. Contact author: Eleni Tsami email: etsami@yahoo.gr 
with it. At the same time they should assist the creation of appropriate educational software.

The Institutes for Professional Training of the Organization for Professional Education and Training are a very good case to study because: every class has 20 25 students (suitable number for an electronic lesson), all of the Institutes lave updated computer laboratories and the Greek Ministry of Education encourage such researches. The research took part in three different classes in different Institutes for Professional Training in Athens - Greece. This paper progresses through the following sections: 'Previous literature and research', 'Research Description and Methology', 'Research restrictions', 'Problems', 'The Programme', 'The Results' and the 'Conclusions'.

\section{Previous Literature and Research}

There are just a few researches and papers published in teaching Economics and all of them are about Secondary Schools and Universities and none of them in Post Secondary level.

The first book is published in 1990 and is one of the most important books on the teaching of courses in Economics "The Principles of Economics Course' by Saunders \& Walstad. Its three component parts refer to: the educational aims and objectives of the introductory course (Economics in the first semester at the universities), the teaching methods and evaluation of teaching.

In 1996 Agarwal and Day in their research, under the title "The Impact of the Internet on Economic Education", presented one of the first empirical analysis examining the educational effectiveness of teaching techniques supported by the internet.

They tested the following null hypotheses against two-tailed alternatives:

1. Internet implementation in economics courses has no impact on student learning and retention.
2. Internet implementation in economics courses has no impact on student evaluations of instructor effectiveness.

3. Internet implementation in economics courses has no impact on student attitudes towards economics. The results of the analysis showed that the addition of Internet based activities and equipment to the education of economics offered very significant advantages in economic learning and the perception of students on the effectiveness of the teacher.

The first hypotheses of this research is the hypothesis of this study not the other two hypothesis number 2 and 3.

Later in 2008, the studies of E. Tsami (2008a), (2008b) on the teaching of economics at the University with the use of new technologies were published. The views of students on teaching through the use of computers were examined. The result of the first survey (2008a) is that students prefer teaching through the use of new technologies at $90 \%$ to traditional teaching.

The results of the second survey (2008b) to the students involved is that: the use of new technologies in the teaching of macroeconomics in relation to the teaching of microeconomics in the traditional mode had neither a positive nor a negative impact.

In this research, we try to study the hypothesis above in the Post - Secondary level. And we are going ti try to compare the results from the Universities and the Institutes for Professional Training of the Organization for Professional Education and Training.

\section{Research Description and Methology}

The paper now turns to discuss the research description and methology. The research conducted for this paper was based on the mentioned literature. The basic hypothesis to be challenged is: "the use of computers and the internet in the teaching of economic modules does not 
affect student learning and retention", posed by Agarwal and Day (1996) in their research.

70 students, in total, participated in the research, comprising three classes of 25, 25 and 20 students respectively. "Money Banks - Elements of Banking Techniques" was the subject taught in these three classes during spring semester 2007-2008.

Fourteen two-hour lessons were delivered in each class, out of which, six were computer based. The computer programme "Macroeconomics" by the Keystone Company was selected as a tool to assist the teaching procedure because it is an introductory and obligatory module for the study of economics. Each of the computerbased lessons comprised, in different format, the material covered, a glossary with the new terms for students, exercises and a knowledge test. How the lessons appeared on the computer screen and the units that were used is illustrated below.

The lessons of the three classes took place in the computer laboratory where 25 computers were installed, allowing the participating students to work individually.

The participating students were all present throughout the course of the research and attended all the six computer based lessons. Each student was given a copy of the programme "Macroeconomics" so as to be able to access the programme through the computer lab as well as his/her home computer. Therefore, students, on their own, could also practise the chapter's questions and exercises, revise and work more carefully on particular difficulties.

Some other students also attended the lessons but they did not take part in the experiment since they were not always present. The 70 students who participated were present in all fourteen computer based lessons.

Students logged on the programme with the help of the tutor, if necessary, and then they were taught the predefined material with the programme's guidance.
Prior to the beginning of the course "Money - Banks - Elements of Banking Techniques", students took a test on part of the syllabus of the course "Transactions' Technique", which the participating students had attended in the lecture hall, during the previous semester, (winter semester 2007-2008). The test consisted of five true-false questions and five multiplechoice questions.

In the final lesson of "Money - Banks Elements of Banking Techniques", students took a test of five true-false questions and five multiple-choice questions based on the taught material. This particular number and type of questions were selected so that the second test on "Money - Banks Elements of Banking Techniques" would have the same format as the first on "Transactions' Technique" in order to be easily corrected and graded. All the 70 students that comprised the three classes completed the test. Moreover, after the completion of the lessons, students filled in a questionnaire expressing their views on computers and the teaching procedure that had taken place both at the computer lab and the lecture hall.

The aim of the research was to assess the results of the two tests in order to compare the knowledge acquired with the use of computers ("Money - Banks - Elements of Banking Techniques") to knowledge acquired without the use of computers ("Transactions' Technique").

The data was selected from the two tests pre - test (exams in the winter semester 2007 - 2008) and post - test (exams in the spring semester 2007 - 2008) and the SPSS 17 Statistic program used to analyse them. $\mathrm{T}$-test analysis selected for this research.

The statistical analyses of the tests are presented in detail in a following chapter.

\section{Research Restrictions}

Research restrictions stipulated that research was carried out at Institutes for Professional Training (IEK) at the Organization for Professional Education 
and Training (OEEK) during the 2007-2008 spring semester. Three different classes selected in three different Institutes for Professional Training in Athens - Greece. A considerable number of students contributed to the research with their views and knowledge so that relevant conclusions could be drawn.

\section{Problems}

Some minor problems emerged in the course of the research. More specifically:

- Gaining access to appropriate bibliographic sources and similar studies that could provide theoretical background was difficult. As mentioned by Simkins (1999) and Sosin (1997) most of the available data has not been published and there are very few empirical studies focusing on the teaching of economics at post-secondary level.

- The computer laboratory was equipped with slow access computers which were often the cause of delays during the computer-based sessions. This problem, however, was not so serious as to cause a lesson interruption.

- Some of the students visited irrelevant web pages and surfed in the internet, during the computer-based lessons, which was the source of slight disruption.

- Some of the students lacked basic computer knowledge. Although the number of the computer - illiterate students was small, slight delays were caused.

- The computer based lessons did not rely exclusively on the electronic format because none of the students made use of the programme on their personal computers. This can be attributed to the following factors: 1) students were not accustomed to such a method of teaching, 2) not all students owned or had access to a computer as the Computer labs at the Institutes for Professional Training (IEK) were, most of the times, occupied by classes which made it impossible for students to enter and use the computers in their free time. Had this been possible they, would have been able to use Word, Excel,
PowerPoint or other programmes for their assignments, and surf the net in search of information as well as visit useful webpages. As a result, the exercises that had to be checked at home remained incomplete.

- There was a difference in the degree of difficulty between the two courses. The course "Money - Banks - Elements of Banking Techniques", which included the six experimental computer-based lessons, is more difficult than the course "Transactions' Technique", taught in a lecture hall. On the other hand, the syllabus of the "Transactions' Technique" course is longer than the syllabus of the "Money Banks - Elements of Banking Techniques" course.

\section{The Programme}

The programme used for the design of the computer-based lesson was 'Macroeconomics' by Keystone Company.

The 'Macroeconomics' CD-ROM is from the key-book ${ }^{+}$series which consists of basic knowledge and reference CD-ROMs addressed to students, pupils, teachers and the wider public that wish to become acquainted with the particular subjectmatter with the use of computer.

In addition, offered features such as electronic bookmarks, notes and printing are additional tools for conquering knowledge. Its philosophy is simplicity, practicality, speed and user-friendliness and it is characterized by substantiality and usefulness. It is rather substantial and utilitarian.

The electronic study aid 'Macroeconomics' CD-ROM of the key-book ${ }^{+}$series was designed bearing in mind that in order to substantially comprehend the laws and operational mechanisms of the economic system critical ability, creative, rational and methodical thinking, as well as continuous linking of theory and practice are essential.

The Macroeconomic material contained in the CD-ROM is presented in two ways: thematically (Concepts - Definitions) and alphabetically (Index) so that they can be 
best comprehended and consolidated. It is divided in 9 units each of which comprises of five sections:

1. Concepts - Definitions, where the material is systematically presented and divided in self-contained parts. The texts are accompanied by photographs and commentary, whereas a great number of concepts are presented with the aid of animation.

2. Comprehension Keys that help for the further knowledge consolidation and systematization as depending on the nature of the section they can contain: in-depth presentation of concepts important for understanding the unit, summary of the basic points, comparative and compositive presentation of the unit's concept groups, methodology presentation and examples of how to solve the exercises for the units that contain exercises.

3. Questions (open type) that test theory comprehension.

4. Exercises that test content comprehension at practical and computational level.
5. Objective type exercises that cover two different categories the answers of which are graded and clocked by the programme:

- Multiple choice exercises where students have to choose one out of five possible answers

- Gap and table filling exercises where students are given either a text with omitted words or a table with omitted numbers and they have to fill in the gaps.

\section{Results}

In this part of the paper we present the data analysis and the findings from the comparisons of the two tests (exams). Table 1 presents the descriptive means of position and dispersion for the students who took part in the research in the lesson of "Money - Banks - Elements of Banking Techniques". 50 students ( 2 classes of 25 students) taught the lessons in the computer laboratories and we named them 'Intervation group' and 20 students taught the lessons in the classroom and this group is named 'Control group'.

Table 1: Group Statistics

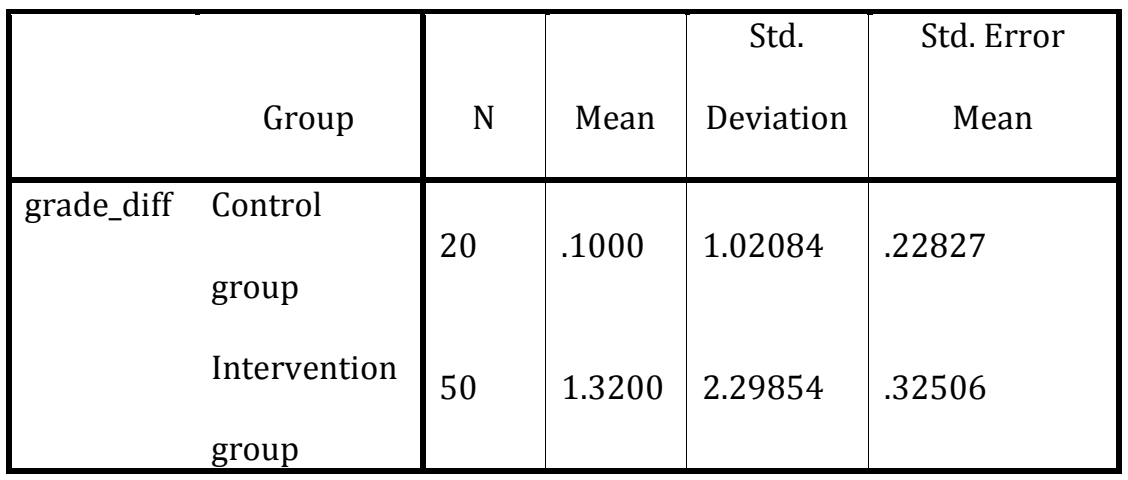

Table 2 presents the Grade of the pre-test for the lesson "Transactions' Technique" for the three different groups of 70 students. The grades ' 15 ' and ' 16 ' are the most popular degrees in the pre - test in the winter semester. 
Table 2: Grade Pre-Test

\begin{tabular}{|c|c|c|c|c|c|}
\hline & & Frequency & Percent & $\begin{array}{l}\text { Valid } \\
\text { Percent }\end{array}$ & Cumulative Percent \\
\hline \multirow[t]{8}{*}{ Valid } & 10 & 3 & 4.3 & 4.3 & 4.3 \\
\hline & 12 & 12 & 17.1 & 17.1 & 21.4 \\
\hline & 14 & 3 & 4.3 & 4.3 & 25.7 \\
\hline & 15 & 18 & 25.7 & 25.7 & 51.4 \\
\hline & 16 & 20 & 28.6 & 28.6 & 80.0 \\
\hline & 17 & 7 & 10.0 & 10.0 & 90.0 \\
\hline & 20 & 7 & 10.0 & 10.0 & 100.0 \\
\hline & Total & 70 & 100.0 & 100.0 & \\
\hline
\end{tabular}

Table 3 presents the Grade of the post-test for the lesson "Money - Banks - Elements of Banking Techniques" for the three different groups of 70 students. The grades '15', '16' and '17' are the most popular degrees in the post - test.

Table 3: Grade Post-Test

\begin{tabular}{|c|c|c|c|c|c|}
\hline & & Frequency & Percent & $\begin{array}{l}\text { Valid } \\
\text { Percent }\end{array}$ & Cumulative Percent \\
\hline \multirow[t]{10}{*}{ Valid } & 10 & 2 & 2.9 & 2.9 & 2.9 \\
\hline & 13 & 6 & 8.6 & 8.6 & 11.4 \\
\hline & 14 & 7 & 10.0 & 10.0 & 21.4 \\
\hline & 15 & 12 & 17.1 & 17.1 & 38.6 \\
\hline & 16 & 11 & 15.7 & 15.7 & 54.3 \\
\hline & 17 & 12 & 17.1 & 17.1 & 71.4 \\
\hline & 18 & 7 & 10.0 & 10.0 & 81.4 \\
\hline & 19 & 9 & 12.9 & 12.9 & 94.3 \\
\hline & 20 & 4 & 5.7 & 5.7 & 100.0 \\
\hline & Total & 70 & 100.0 & 100.0 & \\
\hline
\end{tabular}

Figure 1 illustrates the histograms of the Pre-test grades. As mentioned above, the most popular degrees are ' 15 ' and '16'. 38 students took these degrees or about the $55 \%$ of the students. 


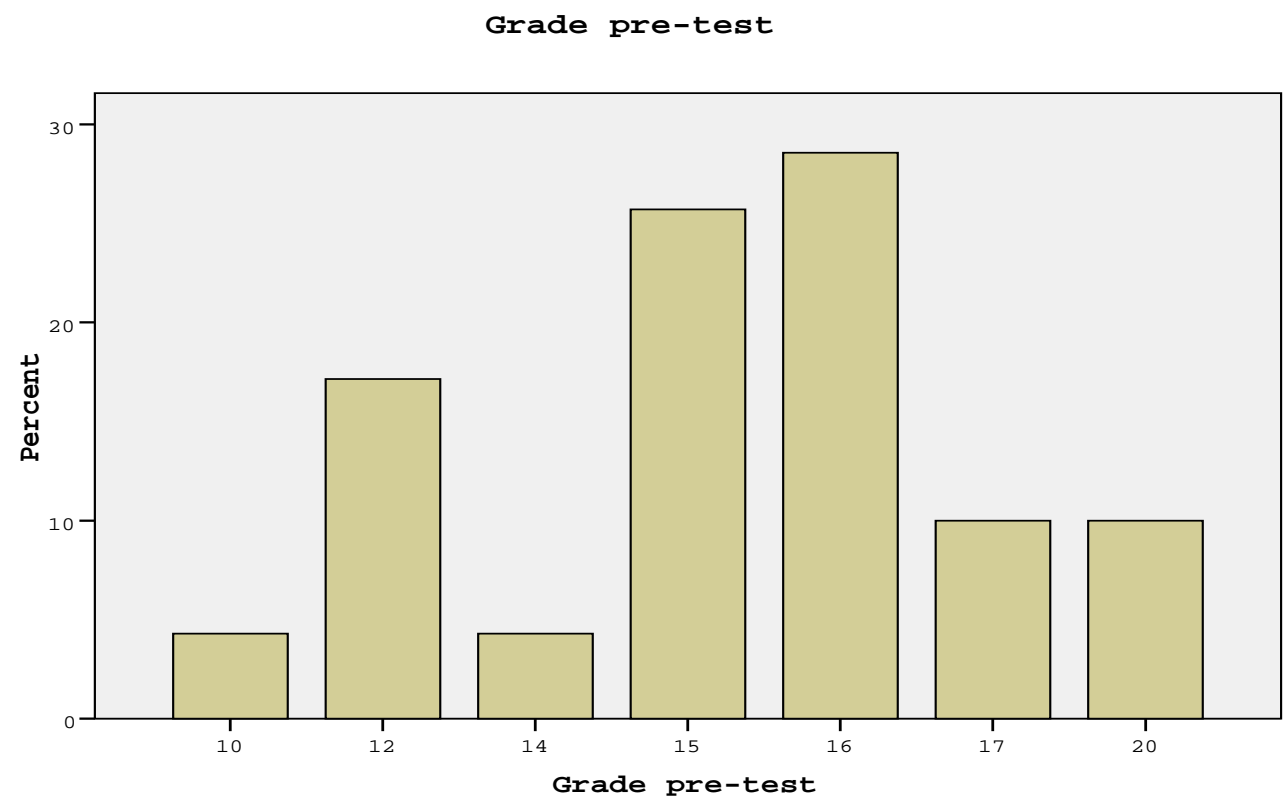

Figure 1: Grade Pre-Test

Figure 2 illustrates the histograms of the Post-test grades. As mentioned above, the most popular degrees are '15', '16' and '17'.
35 students took these degrees or $50 \%$ of the students.

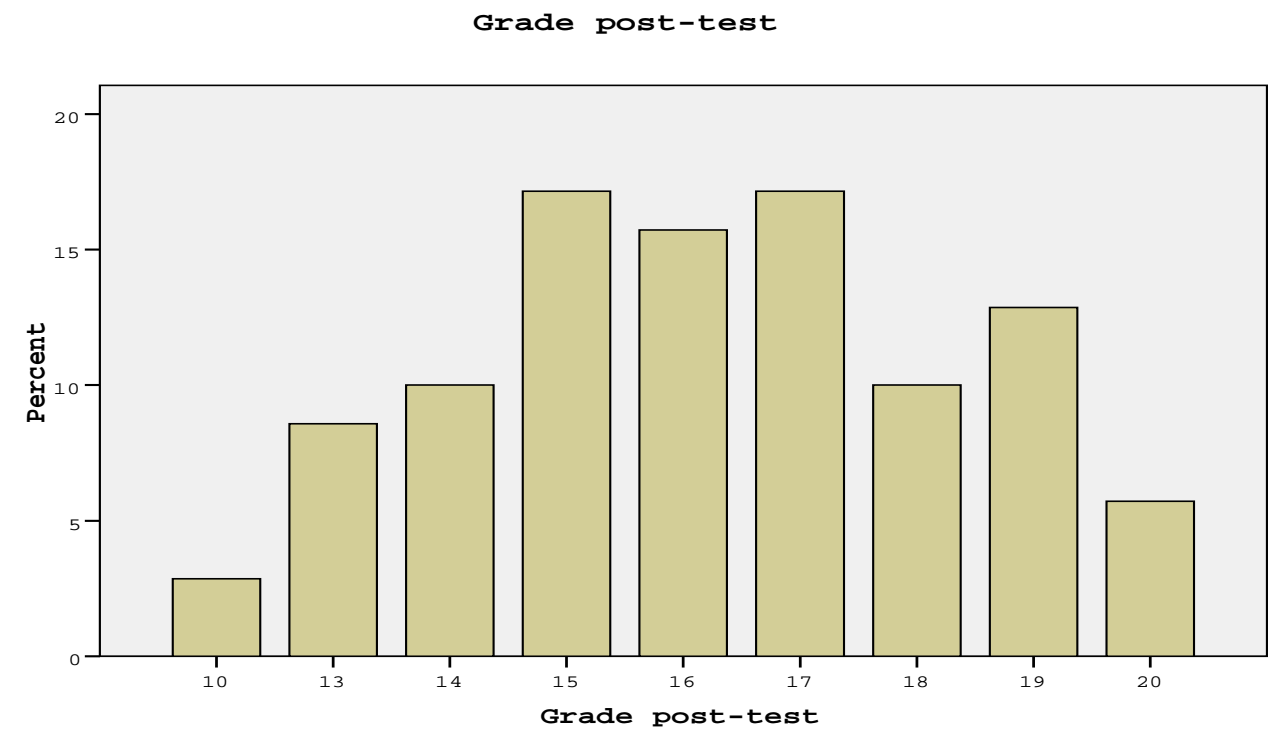

Figure 2: Grade Post-Test 
Table 4: Group Statistics

\begin{tabular}{|ll|l|l|l|l|}
\hline & & & & & Std. Error \\
& Gender & $\mathrm{N}$ & Mean & Std. Deviation & Mean \\
\hline grade_diff & Male & 20 & 1.3000 & 2.34184 & .52365 \\
& Female & 50 & .8400 & 1.98319 & .28047 \\
\hline
\end{tabular}

Table 4 presents the Group Statistics about the grade difference of the gender of the students. The classes attended from 50 female students and 20 male students. The male students get better grades in the tests.

Table 5 presents the Independent Samples Test for grade differences for the lessons
"Transactions' Technique" and "Money Banks - Elements of Banking Techniques".

Thus we observe that there is a statistically important differentiation between the average Pre-test and Post-test grades.

Table 5: Independent Samples Test

Independent Samples Test

\begin{tabular}{|c|c|c|c|c|c|c|c|c|c|}
\hline & \multicolumn{2}{|c|}{$\begin{array}{l}\text { Levene's Test for } \\
\text { quality of Variance }\end{array}$} & \multicolumn{7}{|c|}{ t-test for Equality of Means } \\
\hline & \multirow[b]{2}{*}{$\mathrm{F}$} & \multirow[b]{2}{*}{ Sig. } & \multirow[b]{2}{*}{$\mathrm{t}$} & \multirow[b]{2}{*}{ df } & \multirow[b]{2}{*}{ ig. (2-taileo } & \multirow{2}{*}{$\begin{array}{l}\text { Mean } \\
\text { Difference }\end{array}$} & \multirow{2}{*}{$\begin{array}{l}\text { Std. Error } \\
\text { Difference }\end{array}$} & \multicolumn{2}{|c|}{$\begin{array}{c}95 \% \text { Confidence } \\
\text { Interval of the } \\
\text { Difference }\end{array}$} \\
\hline & & & & & & & & Lower & Upper \\
\hline $\begin{array}{c}\text { grade_d Equal varian } \\
\text { assumed }\end{array}$ & 8.110 & .006 & -2.278 & 68 & .026 & -1.22000 & .53561 & 2.28879 & -.15121 \\
\hline $\begin{array}{l}\text { Equal varian } \\
\text { not assumed }\end{array}$ & & & -3.071 & 67.138 & .003 & -1.22000 & .39720 & 2.01279 & -.42721 \\
\hline
\end{tabular}

Figure 3 illustrates the histograms of the difference in grades between the Pre-test and the Post-test. It is obvious that the students learned more and took better grades in the lesson with the title "Money Banks - Elements of Banking Techniques".

This lesson is more difficult the "Transactions' Technique" but the lessons in the computer laboratory was more effective than the lessons in the classroom.

26 students' score is 1 points higher in the post - test than the score in the pre - test.
The score of students in post-test was 1 point higher on average than the scores of students in pre-test. Therefore teaching with the use of computers was more effective than traditional teaching. This is certainly something that should be investigated in larger scale in other Institutes for Professional Training (IEK), of the Organization for Professional Education and Training (OEEK) and universities in Greece as well as abroad in order to compare and assess results more validly. 


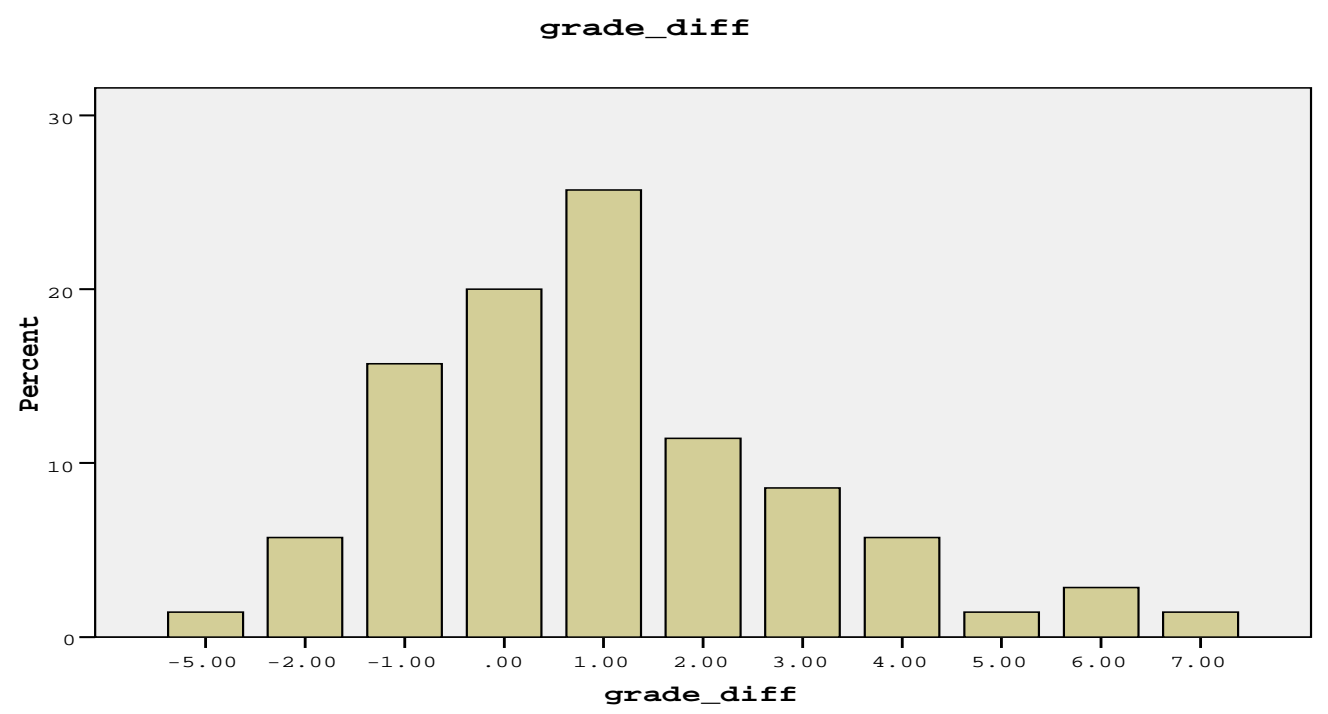

Figure 3: Grade Difference

\section{Conclusions}

Educational software development is at a very early stage in Greece. The inflexibility of our educational system along with the insufficient teacher training in new technologies make the task of incorporating new informatic applications in the teaching process difficult. The teaching hours available for economic modules are few. The number of economic modules at the Institutes for Professional Training (IEK) at the Organization for Professional Education and Training (OEEK) are restricted and most of the courses are choice courses.

New Technologies enhancement of courses facilitates communication between the instructor and students, and easy access of information using the medium promotes use of economic data and real-world applications to enhance the teaching of theory.

The point of using the computer is to add value to the classes that we teach and to allow us to meet the challenges of teaching. The use of new technologies significantly enhances economic education for two reasons. First, contact time with students substantially increases through e-mail and discussion lists. The instructor is able to communicate effectively with many students at the same time through the discussion list. Being able to correspond among them regarding the relevant theory and problems gives students an additional opportunity to focus on problem areas and seek help from each other. We believe the added communications element goes a long way in fostering both thought and interest in the subject matter.

Second, the computer assignments allow students to observe the real-life implications of the economic theory they learn in class. The hands-on experience provides a better understanding of the subject matter and makes the learning process more active.

The area is rich in future avenues for research. Similar studies need to be conducted in universities, colleges and Institutes for Professional Training before one can say with certainty that the use of computer has a positive impact on economic education.

In addition, knowing how the use of new technologies affects students as they progress through the entire economics program, rather than just one course, would be useful. Another interesting question is whether the Internet is more 
effective for good versus poor students. Finally, computer enhanced "distance learning" courses represent innovative ways of reducing the costs of education , but the quality differences between these types of courses and traditional courses needs to be addressed.

Both aspects of new technologies use in economic pedagogy provide a real increase in the quality of education. The results of this study suggest beneficial effects of implementing new technologies enhancements. The hypothesis that the use of computers has no impact on student learning and retention is rejected in favor of a positive influence when scores on a standardized test and the final grade are considered as dependent variables.

In specifically:

- The research ultimately showed that, according to Figure 3, the score of students in post-test was 1 point higher on average than the scores of students in pre-test. Therefore teaching with the use of computers was more effective than traditional teaching. This is certainly something that should be investigated in larger scale in other Institutes for Professional Training (IEK), of the Organization for Professional Education and Training (OEEK) and universities in Greece as well as abroad in order to compare and assess results more validly.

- Clarity in presentation, along with enthusiasm and respect towards student views had the greatest positive influence on lesson evaluation by students. On the contrary, teachers tend to underestimate significantly these two factors and overestimate the importance of being well prepared for the lesson and knowing their subject-matter.

- Students' effort plays a key role to obtaining high grades. Students claiming to have tried harder at a module acquired higher grades. Thus, we could support that tension and the total amount of time spent on studying affects the learning of Economics.
- Different students of Economics learn the subject in different ways. Very little is known about how particular teaching methods influence particular student traits. More recent studies by E. Tsami (2008a) support that student learning styles, dependent, independent or co operational, affect the total of economic knowledge.

- Having studied economics at school was neither a negative factor for student performance at the Institutes for Professional Training (IEK), of the Organization for Professional Education and Training (OEEK) nor did it provide an important advantage. In general, further research is required with larger student samples and from different educational systems.

- Teaching assisted by games and computers is almost as effective as conventional teaching but probably costs more. Computer based study systems appear to be more effective than game and simulations especially for students of weaker performance. Educational programmes are effective because students can reach a standard level of qualification sufficiency in less time but students are not very fond of them. Students enjoy being taught according to their personal style and this increases performance in some cases. In general research results show that the advantages of applying the use of computers in teaching economic modules are controversial.

- The size of the class little affects performance. However, some researches by E. Tsami (2008b) have discovered that larger classes can have negative effects in some economic fields and may influence financial benefits from education. According to Blinder (1991) the issue is of great importance and further research is required.

- Students prefer computer-based lessons over traditional lessons to a very high percentage by E. Tsami (2008a). The conclusions from this research are related to the conclusions of researches carried out at Greek Universities by E. Tsami (2008a), (2008b). 


\section{References}

Agarwal, R. \& Day, A. E. (1998). "The Impact of the Internet on Economic Education," Journal of Economic Education, Spring 1998, 29 (2), 99-110.

Blinder, A. S. (1991). "Research in Economic Education and the Teaching of Economics," Journal of Economic Education, summer 1991, 251-254.

Makridou-Bousiou, D. \& Tsopoglous, St. (2001). 'The Use of Informatics in Economic Education,' Thessaloniki: University of Macedonia.

Saunders, P. \& Walstad, W. B. ed (1990). 'The Principles of Economics Course,' New York: McGraw - Hill.

Simkins, S. P. (1999). "Promoting Active Student Learning Using the World Wide
Web in Economics Courses," Journal of Economic Education, vol. 30, summer, 278286.

Sosin, K., (1997). "Impact of the Web on Economics Pedagogy," Allied Social Sciences Association meeting, January 5, 1997.

Tsami, E. (2008a). “Exploring Students' Views on the Teaching of Macroeconomics at University with the Use of, New Technologies," Romanian Journal of Economic Forecasting vol. 9, no 1, pp 162174.

Tsami, E., (2008b). 'Research on the students' Competences Concerning the Teaching of Macroeconomics at University Using New Technologies in Relation to the teaching of Microeconomics,' Paris International Conference on Education, Economy \& Society, (pp 425-437) Paris July 2008. 